\title{
Enhancing the learning experience of embryology for medical students
}

\author{
Chandni Rajesh Patel \\ Aryan Maleki \\ Sagar Kulkarni
}

Faculty of Medicine, Barts and The London School of Medicine and

Dentistry, London, UK
Correspondence: Chandni Rajesh Patel Faculty of Medicine, Barts and The London School of Medicine and Dentistry, 4 Newark Street, Whitechapel, London EI 2AT, UK Email c.r.patel@smdI5.qmul.ac.uk
This article was published in the following Dove Press journal:

Advances in Medical Education and Practice

\section{Dear editor}

We read with great interest the paper by Kazzazi and Bartlett demonstrating the ability to successfully teach a 2-hour embryology program to first-year medical students in a chronological systems-based manner. ${ }^{1}$ Birth defects are a leading cause of infant mortality, accounting for around $25 \%$ of infant deaths, ${ }^{2}$ justifying the inclusion of embryological education into medical training. As medical students in our clinical years, we have experienced firsthand the use of text and static images to teach embryology in our increasingly crowded curriculum. However, unlike topics such as anatomy that require more factual recall, embryology necessitates a deeper understanding of the physiological processes. Accordingly, teaching styles should reflect this difference as students might struggle to adapt to an unfamiliar form of learning.

The authors identified that most medical students are dissatisfied with current embryology teaching. However, while this paper focuses on final year peers condensing preexisting student knowledge into a single session, the source of student dissatisfaction lies with inadequate initial delivery of teaching in the curriculum. Peer-assisted learning is a valuable source of education, but it is often used as an adjuvant in the later stages of learning rather than as an initial resource. ${ }^{3}$ We believe courses should embrace a more diverse toolkit of teaching styles to engage students from the outset.

Virtual three-dimensional models and animations are becoming more widely used in medical education. They allow students to visualize in greater detail the spatial relationships between embryonic structures and their development over time. ${ }^{4}$ While access to anatomy labs and cadavers might be limited in some institutions, exploration of virtual specimens offers a cost-effective educational resource. In addition, many of these three-dimensional models allow users to edit animations and create annotations. The interactive nature of these programs facilitates self-directed learning in a more visually stimulating way. Integrating these learning tools into curriculums will directly address the feedback given in the paper by Kazzazi and Bartlett where students suggested "more photos/diagrams to target the visually focused learners". ${ }^{1}$

Furthermore, the paper relies solely on student confidence as a marker of attainment. We recognize a core purpose of the teaching is to alleviate student dissatisfaction. However, using only self-reported confidence is too subjective, and it should be used in combination with other more objective assessments, for example, a short quiz before and after the course. Another form of assessment used successfully in 
past studies is asking students to attend semistructured interviews after courses to gather more criticism and clarify any opinions highlighted. ${ }^{5}$ Considering the increased awareness around birth defects and the use of genetic counseling, how we teach embryology to the next generation of doctors is of upmost importance.

\section{Disclosure}

The authors report no conflicts of interest in this communication.

\section{References}

1. Kazzazi F, Bartlett J. Condensing embryology teaching for medical students: can it be taught in 2 hours? Adv Med Educ Pract. 2017;8:797-806.

2. Sadler TW, Langman J. Langman's Medical Embryology. 12th ed. Philadelphia, PA: Lippincott Williams \& Wilkins;2012:117.

3. Ten Cate O, Durning S. Peer teaching in medical education: twelve reasons to move from theory to practice. Med Teach. 2007;29(6):591-599.

4. Azkue JJ. A digital tool for three-dimensional visualization and annotation in Anatomy and Embryology learning. Eur J Anat. 2013;17(3):146-154.

5. Moraes SG, Pereira LA. A multimedia approach for teaching human embryology: development and evaluation of a methodology. Ann Anat. 2010;192(6):388-395. 


\section{Authors' reply}

\section{Fawz Kazzazi \\ Jonathan Bartlett}

School of Clinical Medicine, University of Cambridge, Cambridge, UK

Correspondence: Fawz Kazzazi

School of Clinical Medicine, University of Cambridge, 37 Grange Road, Leckhampton House, Cambridge CB2 IRH, UK

Tel +4477542 2005

Email fk276@cam.ac.uk

\section{Dear editor}

We are pleased to see more students interested in our work. ${ }^{1}$ Patel et al present a unique, but inconsistent take on embryology teaching.

Firstly, we do not believe that the metric used by the authors is relevant to the discussion or warrants justification for the inclusion of embryology into the curriculum. This is because measuring birth defects as a cause of infant mortality is not a good measure of its impact as it will likely reflect chromosomal anomalies. The authors proceed to explain that, unlike anatomy, embryology requires deeper understanding and contains more dynamic processes, including physiology, and so, the teaching style should reflect this. However, this would also compel the teaching of physiology in medical degrees to take a similar approach, and such recommendations would be rejected due to this being an inefficient method of information delivery.

The use of virtual models and animations is a welcome addition to medical education delivery. ${ }^{2}$ We will look to use access to similar tools as a supplement to our teaching course in the future. However, it is likely that, as Patel et al pointed out initially, these are better suited for students to use in their own "self-directed learning" environments.

We are assured that the use of student confidence was, in fact, a suitable marker of attainment. ${ }^{1}$ A short quiz before and after the course is not a good tool to use for many reasons. The first is that this can also act to demotivate students attending sessions; we implore the authors to think back to any lecturers that employed similar tools. Furthermore, in addition to wasting valuable time, such techniques are fraught with bias through question selection and may influence the delivery of the course - subconsciously in an attempt to raise the quiz scores. Again, semistructured interviews are difficult to deliver without being subject to selection and reporting bias. Perhaps we could adopt this, but using an impartial third party to conduct the interviews.

We hope that the authors will carry this enthusiasm to go on to deliver effective embryology teaching at their medical school and help to further educate the next generation of doctors.

\section{Disclosure}

The authors report no conflicts of interest in this communication.

\section{References}

1. Kazzazi F, Bartlett J. Condensing embryology teaching for medical students: can it be taught in 2 hours? Adv Med Educ Pract. 2017;8: 797-806.

2. Azkue JJ. A digital tool for three-dimensional visualization and annotation in Anatomy and Embryology learning. Eur J Anat. 2013;17(3):146-154.

Dove Medical Press encourages responsible, free and frank academic debate. The content of the Advances in Medical Education and Practice 'letters to the editor' section does not necessarily represent the views of Dove Medical Press, its officers, agents, employees, related entities or the Advances in Medical Education and Practice editors. While all reasonable steps have been taken to confirm the content of each letter, Dove Medical Press accepts no liability in respect of the content of any letter, nor is it responsible for the content and accuracy of any letter to the editor.

\section{Publish your work in this journal}

Advances in Medical Education and Practice is an international, peerreviewed, open access journal that aims to present and publish research on Medical Education covering medical, dental, nursing and allied health care professional education. The journal covers undergraduate education, postgraduate training and continuing medical education including emerging trends and innovative models linking education, research, and health care services. The manuscript management system is completely online and includes a very quick and fair peer-review system. Visit http://www.dovepress.com/testimonials.php to read real quotes from published authors. 